\title{
The Impact of Economic and Demographic Factors on Retirement Risks in Albania
}

\section{Olgerta Idrizi}

PHD Cand. Assistant Professor, University Mesdhetar, Tirane, Albania

Besa Shahini

Prof. Dr., Department of Applied Statistics and Informatics, Faculty of Economy, University of Tirana, Albania

\begin{abstract}
C19 The pension system has an important role in developing countries' economies. It is very important in the context of the social security. During the last two decades, pension plan in Albania, has passed important transformation in all aspects. So the first goal is maintaining the stability of this system. The aim of this paper is to analyze the efficiency and sustainability of the existing pension system in the Albania and the identification of key factors, which determine its further stability. We should point out that life insurance market and pension plan in Albania are noticeably underdeveloped compared to other European countries, but in the recent years it has been developing moderately under the influence of various factors. Many economic factors have an impact on it, and some of them are globalization, global economic crisis and expressed instability of financial markets. Other factors like demographic factors: mortality rate, life expectancy and net migration have also impact on retirement risk, but in this paper we will analyze and indicate the most significant economic and demographic factors.
\end{abstract}

Keywords: Pension system, sustainability, economic factors, demographic factors, retirement risk etc

\section{Introduction}

After fall of communism system, 1993, "Social insurance in the Republic of Albania" was enrolled and implemented.. This PAYG scheme would be financed through employers and employees' benefits and would guarantee the fulfillment of socialeconomic rights in the field of life insurance. But in 1995, the financial institutions allowed the implementation of the new voluntary column of private supplementary pensions, for the first time in Albania. This column would provide supplementary benefits for the elderly compared to those of public mandatory scheme. The first private institution started its activity in 2006. The occupation percentage of the third column remains very low for the Albanian market.

In recent years, there are taken a lot of pension system reforms from financial institutions in order to find the best way on this demand. The last reform on this approach was taken on 2015, but there are not seeing any changes from these taken instruments. There are different proposed Plans as solutions of the pay-as-you-go system. The goal of the financial institutions and political reforms is to implement Pension Reforms and creating a financially stable and efficient pension scheme that is based on individual social security contributions, as well that will facilitate the increase of social security contribution growth.

The World Bank offers during all its literature review a three-column system. But going through a detailed observation of this system throughout the countries all over the world and the efforts undertaken to build a sustainable pension system, it is considered as interesting to add two extra columns to then old literature and discuss a five columns pension system. This one is more appropriate for countries like Albania and many other Central and east European countries, which came up from a hard communist regime.

We should underling that the demographic factors are extremely important, not only because of the negative rate between birth and death, but also other factors like unemployment and migration to other countries influences pension system as the revenue from taxes reduce.

Demographic changes and the economic crisis have increased the pressure for pension reform. 
As qualitative methods there are used theoretical comparison analysis about pension systems, life tables analyses, actuarial methods, etc. As quantitative research methods the statistical data analysis, forecasting and other financial calculations are used. The paper contains the analysis of statistics of the period from 2011 to 2018.

\section{Research results}

\section{Overview}

The origin of the name "Pension" comes from England term pension (payment), which in its turn derives from pensio, pension, pensus, pendere (consideration, to consider, payment, to pay) in Latin. Historically, in Albania, pension is defined as a material provision of elder citizens or in case of losing ability of work or losing a supporter The following definitions of the term pension are found in Cambridge English Dictionary:

A regular income paid by a government or a financial organization to someone who no longer works, usually because of their age or health.

An amount of money paid regularly by the government or a private company to a person who does not work any more because they are too old or have become ill.

The payment period usually continues till the end of natural life of the retiree, or sometimes the payments are extended and assigned to the widows/widowers of retirees after their death.

\section{Overview of the European Country and Analysis of the Current Albanian Pension System}

Based on the data in the above table, it can be seen that the first pillar pension income occupies the largest share in the overall pension income for most of the observed countries. This is followed by revenues from paid pension contributions in the second and third pillar. The largest revenue in the context of the second pillar of pension insurance is in the Netherlands and the United Kingdom, while the dominance of the first pillar is most common in Italy, followed by Croatia, Germany and France. This distribution of income depends on the structure of the pension insurance system of a country, its executed reforms, demographic trends, economic indicators and historical tradition of individual areas of Europe.

\begin{tabular}{|l|l|l|l|l|}
\hline Country & First column & Second column & Third Column & Total \\
\hline Germany & $65 \%$ & $19 \%$ & $16 \%$ & $100 \%$ \\
\hline France & $60 \%$ & $22 \%$ & $18 \%$ & $100 \%$ \\
\hline Italy & $85 \%$ & $10 \%$ & $5 \%$ & $100 \%$ \\
\hline Netherlands & $30 \%$ & $53 \%$ & $17 \%$ & $100 \%$ \\
\hline United Kingdom & $30 \%$ & $45 \%$ & $25 \%$ & $100 \%$ \\
\hline Croatia & $80 \%$ & $15 \%$ & $5 \%$ & $100 \%$ \\
\hline
\end{tabular}

Table 1. Income from pension contribution paid to the three pillars of insurance in certain European countries (in \%) (Source: CEA, Insurers of Europe, statistics report, 2015)

The institutions represent pension systems in the second pillar of the European Union, whose fundamental objective is to solve problems that arise in the system of state pensions (first pillar) caused by demographic and economic fluctuations, especially in times of financial crisis which has affected all parts of Europe in recent years. Such systems can be set up as voluntary or mandatory depending on the organizational form and the degree of coverage of employed in each Member State of the Union.

The experience of recent decades has shown that many countries are transforming pension systems from mono-pillar version to the multiple one. Multiple-pillar pension systems are more appropriate to meet the goals and objectives that a pension scheme should have.

In many Western European countries the term "second pillar" is often associated with the supplementary pension schemes set up under collective labour agreements. Reforms of the PAYG system started in 1993 resulted not so effective and 
efficient, so the pension reform is under the main priorities of the Government. , The main intervention in this sector was undertaken in 2002 and the last one in 2014. The strategic objective of the Government is to develop the second and the third pillars of pension system, as the first pillar is not any more attractive, due to many changes in Albanian context through years. Based on the solidarity among generations characteristic, the PAYG system provides immediate benefits for retired people, but creates little or no contributions to those who are of working age. For this reason, the unfinanced pension system PAYG is vulnerable to risk. PAYG scheme works well when the rate of increase in labour force participation is the same as the rate of natural growth of the population.

The new system born from the new legislation consists on two different columns. The first own is the required column and the second is the additional volunteer one. The funds of this system are uniquely managed by Social Security Institution, a public entity and covered all types of categories. As mentioned, the actual system has got its problems that need to be resolved.

This one new system is more appropriate for countries like Albania and many other Central and east European countries, which came up from a hard communist regime.

Now we can see the Columns that referred to the Pension system Plans:

The zero Column: help with benefits associated with poverty reduction. This Column derives from retirement payments that are made for individuals who have reached retirement age and doesn't have contributed during their lifetime because they were unemployment or because they did not want to contribute to pension schemes.

First Column: This column, mainly tend to protect the elderly from poverty, which is part of the redistributive function of the state. This scheme is called generation relationship, as current contributors pay to get benefits those citizens who are currently retired. This is the so called model of Pay as You Go, the one that Albania is applying.

Second Column: This column is a combination between a private scheme and the public pension system and is based on capitalization or redistribution, but it should to be clearly separated from the first column. Under this scheme, part of the mandatory contribution will be administered by the public scheme Pay as you go (current scheme: solidarity between generations), which will guarantee a basic pension while the rest will be administered by private companies. These companies will pay the pension when the retirement age will arrive, based on the paid compulsory contribution along with the gain realized over the years.

Third Column: This scheme is completely independent and not under the state control. Under this scheme, the persons are free to contribute. A voluntary funded and privately managed retirement system. This means that all the people who aspire for higher pensions than normal can become part of these schemes. The private pension scheme is still an area to be explored and needs further reforms in Albania to be real effective.

Fourth Column: This is also a non-funded system. Here, we find more social aspects of the scheme, such as family support, health care, and so on.

The right to receive a pension in one of these schemes belongs to everybody who has reached retirement age. (Blake, 1992)

\section{Demographic Impact on Pension System and his Stability}

The challenges of this pension system depend on the country's demographic and economic developments (Holzmann et al , 2008)::

Projections in Albania, as many part of the world show that in the near future the percentage of working age population will decrease, compared to the percentage of pensioners. This phenomenon is called "population aging". The aging of the population is accompanied by an increase in the fiscal burden that the government has to afford to pay for pensions. (Baldwin, 2009).

Another important object for accelerating the aging of the population has been immigration. In Albania, the Immigration began after the 1990s as a phenomenon and according to an valuation by the International Organization for Migration (IOM) Albania has had a migratory population rate for the last two decades by the highest number of people in the world. According their analyze, almost $25 \%$ of the population migrate and most of them were young men (IOM - Migration in 
Albania country profile 2016). The Albanian transition from a centralized economy to a free market led to the creation of private enterprises, which at the beginning were more focused on services and were small enterprises. The process of creating new jobs was at very low rates. According to the Labour Force Survey organized by INSTAT in 2017, the unemployment rate was $11 \%$. According to the same survey, the participation rate in the labour force for the population of $30-64$ years old is $77 \%$, while the employment rate is $68.7 \%$. The labour market in Albania was also associated with a high degree of informality. Most of the working people do not declare themselves employed, thus avoiding social security payments. (INSTAT, 2018).

The Albanian Social Insurance Scheme is managed by the Social Insurance Institute, which is an independent public institution whose organization and operation is regulated by law. It is governed by the administrative council and the general director.

The mission of the Social Insurance institute is focused in the administration of the social security plan and to pension policies, casing the population with social security elements in each country and time when it is proper, increasing so the number of contributors and collecting income from farmers' and volunteer contributions, improving efficiency in the management of social security funds, temporary free funds and reserve funds.

We should take into consideration that pension reforms are needed in order to reduce the risks, which is affected by demographic, economic and politics factors.

Germany, Italy, Portugal and Spain are affected by the most severe demographic problems. As to the UK and France, this problem does not have such an impact on the population due to higher birth rate (Axel, Karsten, \& Hendriks, 2005). In case of Albania, the demographic factors are extremely important. Not only the ratio between birth rate and death rate is negative, as it was mentioned before, but also the so called "envelope salaries", unemployment and migration to other countries influences pension system as the revenue from taxes reduce, thus making less contributions to the pension fund. As a result, the state is forced to raise taxes, which slows down the economic development.

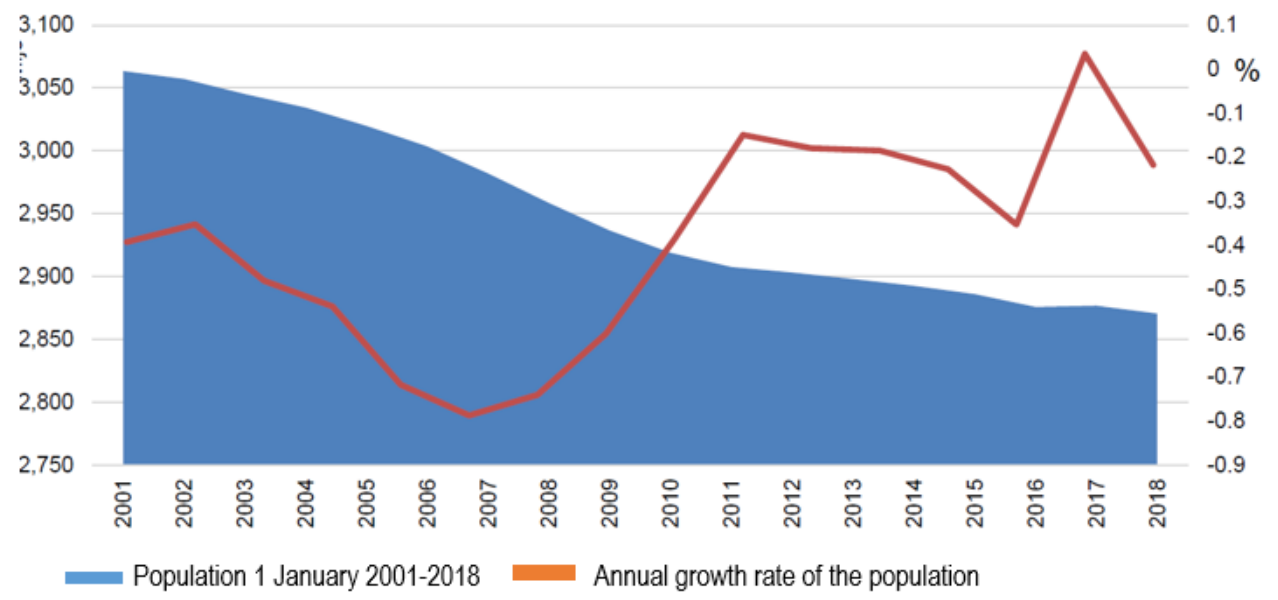

Graph 1 Population of Albania from 2011 to 2018 and Annual growth rate of the population (Source: INSTAT 2018)

From the graph 1 we can clearly see that the annual growth of the population is increased based on the passed years. 


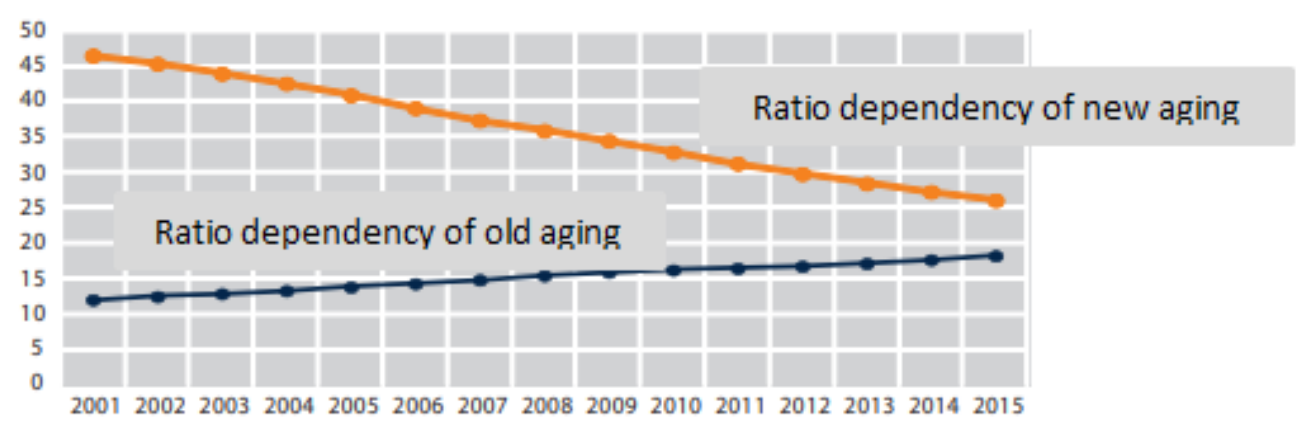

Graph 2. Ratio of dependency aging. (Source. INSTAT. 2016)

The average population on 2015 has a decrease from 2014 year.

The two main components of the population are: natural population supplements and net migration. Natural populations have declined compared to the previous year by about $31 \%$, as a result of the decrease of births by $8.5 \%$ and the increase of deaths by $8.5 \%$ compared to 2014 . On the other hand the second component, net migration marks the value of $-17,000$ during 2015 , thus giving a significant impact on population cuts.

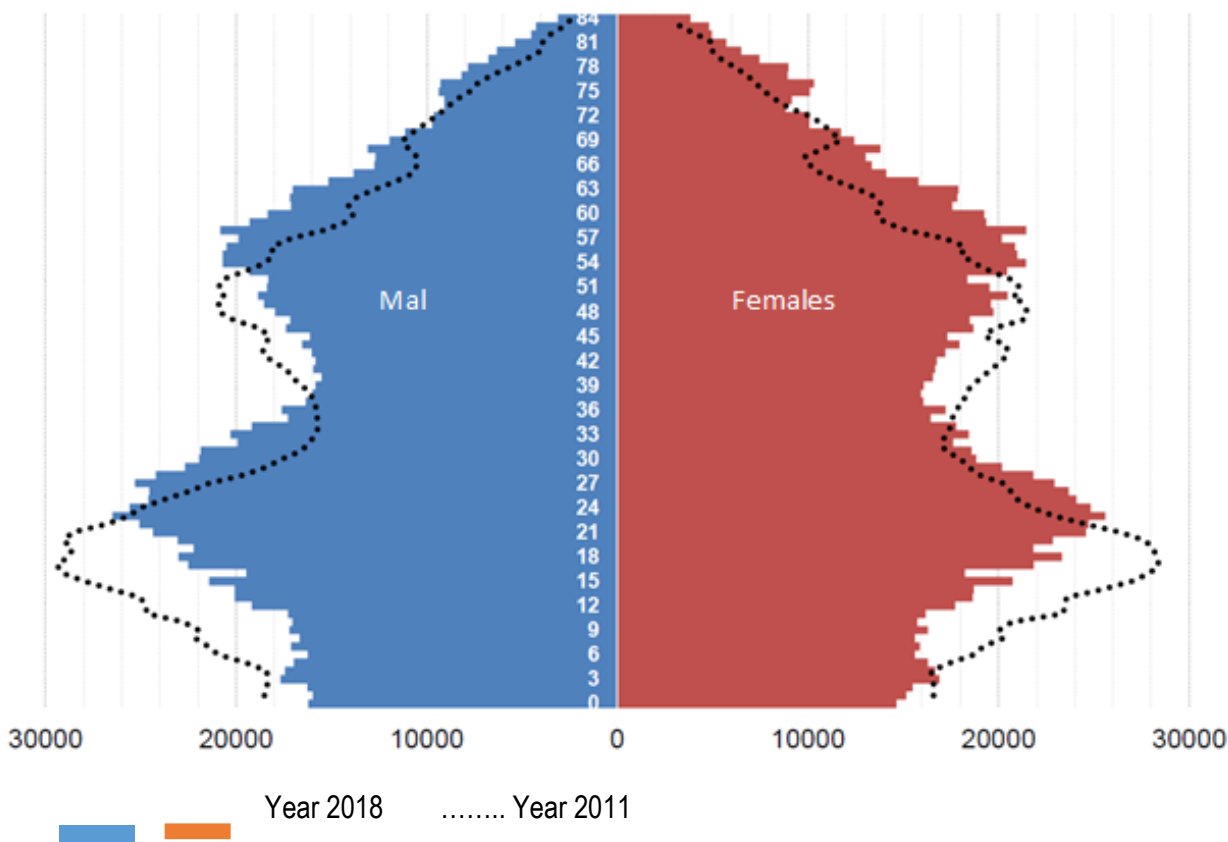

Graph 3. Pyramid of population 1 January 2018 (Source: INSTAT 2018)

The population pyramid gives a clear illustration of the population by age, group and gender. The graph reflects the pyramids of the population for two years 2011 and 2018. During this 7 years period there is a clear tendency towards aging population reduction of the pyramid base as a result of lowering the number of births and increasing in the upper pyramid such as the result of an increase in life expectancy. The dependency ratio of the elderly is calculated as a 65 -year-old population ratio over the working-age population of 15-64 years; for 2015 this ratio in Albania is $18.2 \%$ versus $12.0 \%$ in 
2001. (Guxho 2015) This report expresses a growing trend over the years. The ratio of youth dependency is calculated as a ratio of the population aged 0-14 years to the working age population of 15-64 years. This report for the year 2015 is $26.1 \%$ versus $46.5 \%$ in 2001 . Clearly, a drop in this report in our country is almost at its halving. The overall dependency ratio shows a downward trend, as the decline in the youth dependency ratio has a greater effect than the increase in the dependency ratio of the elderly. Thus, the weight to be borne by people of working age, for the support of young people and the elderly has decreased from $58.5 \%$ in 2001 to $44.3 \%$ in 2015 .

Albanians today live on average 1 year more compared to 2011. In 2015, life expectancy for women is 79.7 years and 76.1 years for men. Unlike the general trend 2011-2015, compared to 2014, there is a slight decline in life expectancy at birth for both sexes. During 2015, the number of births decreased by $8.5 \%$ compared to 2014 . Albanians today live on average 1 year more compared to 2011. (Instat. 2018)

Albania's aging population, from $7.6 \%$ of the elderly in 2001 today we have $12.6 \%$ of the elderly.

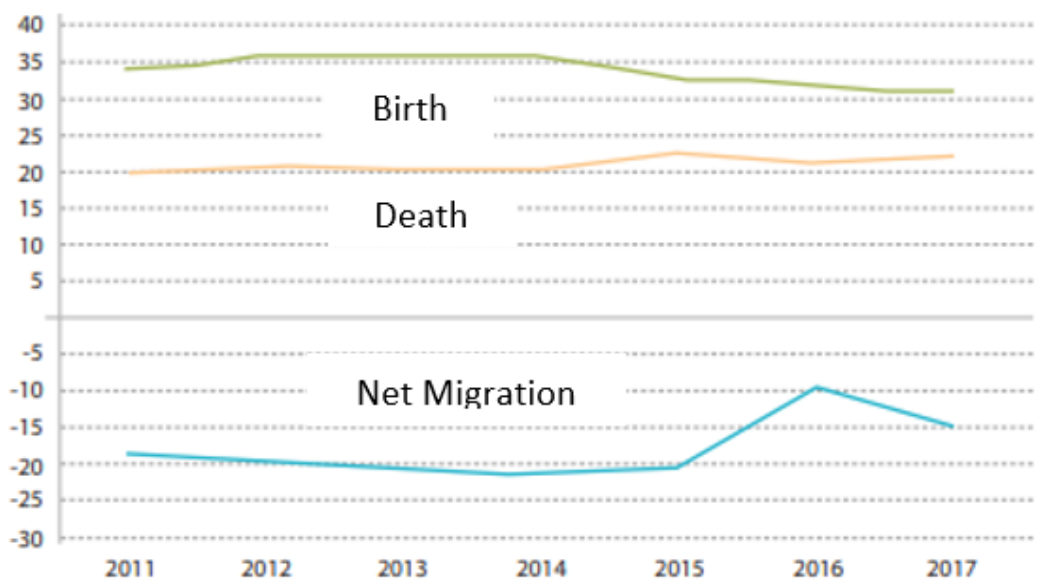

Graph 4. Trend of demographic factors in Albania. 2011-2017 (Source. Instat)

Considering the negative tendency of demography and migration, during the following years and economic development the issue of labor approachability will become more and more urgent in Albania. Till now improvement of Albania competitiveness was basically determined by reducing labor costs. However, it should be mentioned, that to maintain the advantages of low cost labor in long term would not be possible under conditions of labor market liberalization and international mobility of the workforce.

This situation will not continue longer, because employees now need to save money for our pensions and help others, but with Albania average salaries it is not possible. Respectively, in order to improve the situation positively, the birth rate should increase two fold from what it is today.

The problems that Albania is facing today and will face over the future ten or twenty years such as migration, low birth rate, aging of society and the changes in national economy and economy, in general, as a result of the crisis leads to the fact that the burden on the social security budget will keep growing.

Initially the aim of Pension Level 2 was not only to increase pension capital, ensuring full value pensions in future, but it was meant to facilitate the development of national economy. It had to become the driving force of national economy.

Currently the money mostly is invested in short-term deposit savings where its profitability is much lower than inflation, so money loses it value. Financial means are also invested in state bonds. Bonds accumulate money for the state budget, which goes to consumption but not into state investments in the long term. 


\section{Conclusions}

The pension system is an extremely important part of the social security of every individual or the society in which it is located. Its sustainability is significantly affected by the economic, but even more the non-economic factors.

Pension fund from the first pillar dominates the largest share of total pension income in Albania, but the second pillar in Albania significantly differ from other observed countries of the European Union.

Current low engagement of improvement reduces the possibility to achieve rapid development of macroeconomic indicators.

Since most of the population represented do not participate in the voluntary pension insurance column the necessity of complete harmonization of the Albania pension system with the European social model will be of great importance in the coming period. They think that the investments from voluntary pension funds are ineffective and they do not have money for that type of investments.

The contributions into Pension Level 2 should be increased gradually, until it is comparative with the Pension Level 1 contributions, making it possible for people to make savings for pensions.

The Albania government has to pay attention to the pension Level 3 system. The accumulation system should be introduced when working people make contributions into private pension funds and receive later pension from those savings that have been made.

In addition, respondents identified themselves as partly satisfied in relation to the functioning of the current structure of the pension insurance system, and expressed their greatest dissatisfaction with the inefficiency of the current system and its long-term unsustainability.

In order to reduce the informal labor force, it is necessary to improve competitiveness of tax system. Reduction of tax burden on business and employment must be achieved.

The demographic changes have an impact on the risk of pension systems. In order to reduce the negative impact of demographic changes on production modernization, it is necessary to encourage increase of professional education and the lifelong education system, by ensuring accordance between labor supply and demand, through putting emphasis on improvement of employee skills and increasing professional mobility.

It is necessary to consider seriously migration issues (immigration and emigration) policy, so that it contributes to a qualified workforce and enhances economical growth. Yes, we might agree, that they help in covering state subsistence costs, but it is unlikely that they will be able to create added value to economy.

As we see the economic and demographic factors have an impact on pension plan. We should try to improve with the political and legal policies in order to reduce the risk of mortality and economic risk. We can suggest making an actuarial calculation in 2 years in order to get better results on actuarial science, so we can predict the right pension system.

\section{References}

[1]Axel, Karsten, \& Hendriks (2005), The Survey of Health, Aging, and Retirement in Europe - Methodology

[2] Blake, D. (1992).Modeling pension fund investment behavior. London: Routledge

[3] Baldwin, B. (2009). Research Study on the Canadian Retirement Income System, Canada

[4] Beck, T., Webb, I. (2003) "Economic, demographic and institutional determinants of life insurance consumption

[5] Browne, M. J., Kim, K. (1993) "An International Analysis of Life Insurance Demand"

[6] Eurostat (2013). European Social statistics .ISSN 1977-7930

[7] Fiche , C (2017). Pension Projections exercise 2018. Germany

[8] Lama, A. (2005) "Insurance System Development, The necessity of Social Insurances and Private Pensions in Albania. 
[9] Lee, C., Chiu, Y. (2012) "The impact of real income on insurance premiums: Evidence from panel data"

[10] Guxho, A (2014). Pension scheme in Albania and actuarial forecasting., Dissertation, University of Tirana

[11] Holzmann, R., MacKellar L, Repansek J, (2008). Pension Reform in Southeastern Europe Linking to Labor and Financial Market Reforms.

[12] ILO estimates and projections of the economically active population 1990-2020 (sixth Edition)

[13] Prill 2014, Dokumenti I politikave te Pensioneve

[14] Privat Pension System in Albania, Gert Dragoshi \& Ledian Shahini, 2016

[15] Xhumari, M. (2000). Welfare programs for unemployment income in Albania, published by FISS

[16] www.worldbanok.org/pension

[17] www.instat.gov.al

[18] www.issh.gov.al

[19] www.amf.gov.al 